\title{
BMJ Open Late-life suicidal behaviours among new users of antidepressants: a prospective population-based study of sociodemographic and gender factors in those aged 75 and above
}

Khedidja Hedna, ${ }^{1}$ Karolina Andersson Sundell, ${ }^{2,3}$ Gunnel Hensing, ${ }^{2}$ Ingmar Skoog, ${ }^{1}$ Sara Gustavsson, ${ }^{4}$ Margda Waern ${ }^{1}$

To cite: Hedna K, Andersson Sundell K, Hensing G, et al. Late-life suicidal behaviours among new users of antidepressants: a prospective population-based study of sociodemographic and gender factors in those aged 75 and above. BMJ Open 2018;8:e022703. doi:10.1136/ bmjopen-2018-022703

- Prepublication history and additional material for this paper are available online. To view these files, please visit the journal online (http://dx. doi org/10.1136/bmjopen-2018022703).

Received 5 March 2018

Revised 8 July 2018

Accepted 11 September 2018

D Check for updates

(C) Author(s) (or their employer(s)) 2018. Re-use permitted under CC BY-NC. No commercial re-use. See rights and permissions. Published by BMJ.

For numbered affiliations see end of article.

Correspondence to

Dr Khedidja Hedna;

khedidja.hedna@neuro.gu.se

\section{ABSTRACT}

Objective To investigate sociodemographic and gender factors associated with suicide and suicide attempts among new users of antidepressants aged 75 and above. Design Register-based cohort study.

Setting National population-based cohort of Swedish residents aged $\geq 75$ years.

Participants 185225 patients who initiated antidepressant medication between 1 January 2007 and 31 December 2013 were followed until 31 December 2014.

Main outcome measures Suicide and suicide attempts. Fine and Gray regression models were used to analyse the sociodemographic factors (age, country of birth, marital status, education level, last occupation, income and social allowance) associated with suicidal behaviours in the entire cohort and by gender.

Results During follow-up, 295 suicides and 654 suicide attempts occurred. Adjusted sub-hazard ratios (aSHRs) for suicide were lower among older age groups (aSHR $0.73,95 \% \mathrm{Cl} 0.53$ to 0.99 for those $85-89$ years; and aSHR $0.53,95 \% \mathrm{Cl} 0.33$ to 0.86 for those $\geq 90$ years). A similar pattern was observed for suicide attempts. Suicide attempts were more common among those born in foreign countries (aSHR 1.58, 95\% Cl 1.16 to 2.15 for those born in another Nordic country; and aSHR $1.43,95 \% \mathrm{Cl}$ 1.06 to 1.93 for those born in non-Nordic countries). In the gender-stratified analyses, being single or divorced, and born in another Nordic country was associated with a higher risk of suicide among men. Educational and occupational history and being born in a non-Nordic country influenced risk of suicidal behaviours in women. Conclusion Suicidal behaviours occurred more commonly among new users who were 'younger' old adults and those with foreign background, suggesting that those groups might require greater support when initiating antidepressant therapy. Our findings suggest the need for gender-specific, multifaceted approaches to the prevention of suicidal behaviours in late life.

\section{INTRODUCTION}

High suicide rates are observed in older adults in many countries. ${ }^{1}$ The most common
Strengths and limitations of this study

- This is the first prospective cohort study to focus on the sociodemographic factors associated with suicidal behaviours among the oldest adults who initiated an antidepressant therapy.

- The study is based on a national population-based cohort with no exclusion criteria, minimising the risk of selection bias. Moreover, there is no recall bias as national registers were used to define the sociodemographic factors and potential confounders.

- Only suicide attempts that have been registered in hospitals or specialised outpatient services can be captured with our study design.

- Research is needed in other settings as socioeconomic conditions, availability of healthcare and cultural differences may have an impact on suicidal behaviours in late life.

contributing factor to the development of selfharm behaviours in late life is the presence of clinically significant depressive symptoms. ${ }^{2}$ Therefore, most suicide prevention strategies have focused on increasing the detection of depression and optimising its management. ${ }^{3}$ However, the long-term benefits and sustainability of such programmes remain uncertain. ${ }^{45}$ While suicide rates are particularly high in older adult men, ${ }^{6}$ prevention programmes appear to be more successful in women than in men. ${ }^{4}$

One possible explanation for the limited success of depression-focused interventions in reducing the prevalence of suicidal behaviours in late life is that these behaviours have a multifactorial aetiology. Untargeted factors such as loneliness, limited social support and financial concerns may drive the association between depression and suicidal behaviours. $^{7-9}$ 
The role of social factors in late-life suicidal behaviours is relatively little studied. Despite broad inclusion criteria, a recent systematic review identified only 16 studies with a focus on social factors in late-life suicidal behaviours. ${ }^{8}$ Few of these involved persons in their upper seventies, eighties and nineties, which is the segment of the population with particularly high rates of suicide. ${ }^{10}$ Results from studies focusing on 'younger' older adults (under 75 years) cannot be extrapolated to older persons. Risk factors have been shown to differ with age in both clinical and population-based cohorts of older adults. ${ }^{11} 12$

Better recognition and management of factors associated with suicidal behaviours are important targets for the prevention of suicide in the oldest population, especially in the context of depression. Given that antidepressants are commonly prescribed for depression, ${ }^{13-15}$ their use may be considered as a proxy for depressive disorders. The objective of this study was therefore to investigate the association between sociodemographic factors and risk of fatal and non-fatal suicidal behaviours in a national population-based cohort of Swedish adults aged $\geq 75$ years who initiated antidepressant therapy.

\section{METHODS}

\section{Study population and data sources}

We conducted a population-based cohort study among all Swedish residents aged $\geq 75$ years who filled at least one antidepressant prescription between 1 January 2007 and 31 December 2013 and had not filled any antidepressant prescription in the preceding 12 months. The date of the first filled prescription represented the index date. These individuals $(\mathrm{n}=185225$, mean age: 83.4 years, age range: 75-110 years) were followed from their index date until 31 December 2014 or until migration or death. Data on dispensed antidepressant medications (defined by the Anatomic Therapeutic Code ATC-N06A) were obtained from the Swedish Prescribed Drug Register held at the National Board of Health and Welfare. ${ }^{16}$ The register includes purchased prescribed drugs for outpatients, residential care and nursing homes. Sociodemographic data were collected, by record linkage, from the longitudinal integration database for health insurance and labour market studies (LISA) and the Total Population Register, held by Statistics Sweden. Persons residing in nursing homes were identified by data from the care and social services from the National Board of Health and Welfare.

\section{Outcome measure}

The study outcomes were the occurrence of suicide or suicide attempt, identified from the Cause of Death Register, and from the National Patient Register, respectively. Both registers are held by the National Board of Health and Welfare. The outcome measures were coded according to International Classification of Disease-10: intentional self-harm (X60-X84), harm of undetermined intent (Y10-Y34) and sequelae of intentional self-harm and of events of undetermined intent (Y87.0 and Y87.2).

\section{Sociodemographic factors}

We collected sociodemographic data as recorded during the year preceding the index date. Participants' characteristics included: sex, age group $(75-79,80-84,85-89$ and $\geq 90$ years) and number of household members (1, 2 and 3 or more). We grouped marital status into four categories: single, married, divorced and widow/ widower. Country of birth was grouped into three categories: Sweden, Nordic countries and other. The highest attained level of education was categorised into mandatory, secondary and higher education. We categorised the last registered type of occupation as: upper white collar; lower white collar blue collar and others. The latter category included armed forces, farmers, market gardeners, forestry workers and related occupations. Annual income was categorised in tertiles. We also considered whether individuals had received social allowance during the year preceding the index date.

\section{Healthcare facility}

We categorised the healthcare facility that issued the index prescription according to the type of care: primary, specialised ambulatory care, hospital, home care and other. Spheres of activity were characterised as: primary care, psychiatry, geriatrics, emergency, internal medicine, neurology, palliative, home care, convalescent and day care, and other.

\section{Statistical analysis}

We used the Fine and Gray proportional hazard model ${ }^{17}$ to identify factors associated with suicide and suicide attempt. Independent sociodemographic variables included in the model were: sex, age, marital status, country of birth, level of education and occupational category. We also considered the type of the healthcare facility where the index prescription was issued. We adjusted the regression model for residence in nursing home during the year preceding the index date as a general marker of frailty. As attempted suicide is a strong predictor of future suicidal behaviours, models were also adjusted for suicide attempt during the year prior to the initiation of antidepressant therapy. The number of household members was not included in the regression model because of its association with the marital status. A very small proportion of individuals had social allowance $(0.4 \%)$. This variable was not included in the regression models. We analysed the data for the entire study population as well as for men and women separately. Data analyses were performed by SAS V.9.4 (SAS Institute. NC, USA).

\section{Patient and public involvement}

No patients were recruited for this study as it was based solely on national register data. No patients were directly involved in setting the research question or the study measures, and none were asked to advise on interpretation or writing up of results. The study questions were inspired by our research interviews with close relatives of older adults who died by suicide, ${ }^{11}$ and with older patients 
hospitalised in connection with self-harm, ${ }^{18}$ as well as our ongoing focus group study on older men and women's experiences of being depressed and being in treatment for depression. Our research is carried out within the AgeCap Center, a multidisciplinary research centre on ageing, and results will be disseminated to the older adult community through our AgeCap newsletter, and other public activities. Results will also be disseminated to health and social service professionals who work with older adults through our group's regional and national educational activities for service providers.

\section{RESULTS}

Table 1 includes the baseline sociodemographic characteristics of the study population. Almost two-thirds who were women. Sixty per cent lived alone. Most were born in Sweden and few received social allowance during the year preceding the initiation of their antidepressant therapy.

As previously reported, ${ }^{19}$ half of the cohort had a prescription for citalopram, and one-fifth were on mirtazapine. Over two-thirds received their index prescription in a primary care setting (table 2). Fewer than 1 out of 12 initiated their antidepressant therapy within psychiatric services.

Suicide was the cause of death for 295 individuals (199 men and 96 women), corresponding to an incidence rate of 50 per 100000 person years for the total study population. As previously reported, ${ }^{19}$ hanging was the most common method in men; poisoning was the dominant method among women. Suicide methods are shown by sex in online supplementary appendix 1. In total, 654 persons (300 men and 354 women) attempted suicide, yielding an incidence rate of 117 per 100000 person years for the total study population.

Table 3 shows that the adjusted sub-HR (aSHR) for suicidal behaviours was significantly higher among men for both suicide (aSHR 3.56, 95\% CI 2.67 to 4.73), and suicide attempt (1.41, 95\% CI 1.17 to 1.68$)$. A lower risk of suicide was observed among antidepressant new users aged 85 years and over compared with those aged 75-79 years. A similar result was observed for suicide attempts. We found a higher risk of suicide attempts among those born outside of Sweden: (1.58, 95\% CI 1.16 to 2.15) for those born in another Nordic country, and for those born in non-Nordic countries $(1.43,95 \%$ CI 1.06 to 1.93$)$. The risk of suicide was higher among those who were single $(1.81,95 \%$ CI 1.21 to 2.70$)$ or divorced $(1.43,95 \% \mathrm{CI}$ 1.02 to 2.01) compared with those who were married when initiating their antidepressant therapy. The level of education impacted differentially on fatal and non-fatal suicidal behaviours. The risk of suicide was lower among those with secondary education compared with those with mandatory education only $(0.71,95 \% \mathrm{CI} 0.51$ to 0.99 ), while the risk of suicide attempt was higher (1.60, 95\% CI 1.27 to 2.01 ) among those with a higher education. Neither income nor occupational history were
Table 1 Baseline characteristics of new users of antidepressants aged 75 and above $(n=185225)$

\begin{tabular}{|c|c|}
\hline Characteristics & $\mathbf{N}(\%)$ \\
\hline \multicolumn{2}{|l|}{ Sex } \\
\hline Women & $117606(63.5)$ \\
\hline \multicolumn{2}{|l|}{ Age group (years) } \\
\hline $75-79$ & $53126(28.7)$ \\
\hline $80-84$ & $56223(30.4)$ \\
\hline $85-89$ & $47678(25.7)$ \\
\hline$\geq 90$ & $28198(15.2)$ \\
\hline \multicolumn{2}{|l|}{ Number of household members* } \\
\hline 1 & 110500 (59.7) \\
\hline 2 & $72160(39.0)$ \\
\hline$>2$ & $2537(1.4)$ \\
\hline \multicolumn{2}{|l|}{ Marital status* } \\
\hline Widow/widower & $79703(43.0)$ \\
\hline Married & 73059 (39.4) \\
\hline Divorced & $21619(11.7)$ \\
\hline Single & $10816(5.8)$ \\
\hline \multicolumn{2}{|l|}{ Country of birth } \\
\hline Sweden & $167586(90.5)$ \\
\hline Nordic countries (except Sweden) & $8488(4.6)$ \\
\hline Non-Nordic countries & $9151(4.9)$ \\
\hline \multicolumn{2}{|l|}{ Highest level of education } \\
\hline Mandatory school & $108573(58.6)$ \\
\hline Secondary school & $42298(22.8)$ \\
\hline Postsecondary or higher & $34354(18.5)$ \\
\hline \multicolumn{2}{|l|}{ Last occupation } \\
\hline Upper white-collar worker & 36826 (19.9) \\
\hline Lower white-collar worker & $23622(12.8)$ \\
\hline Blue-collar worker & $91932(49.6)$ \\
\hline Other & $4518(2.4)$ \\
\hline Unknown & $28327(15.3)$ \\
\hline \multicolumn{2}{|l|}{ Annual income (Swedish Crowns)* } \\
\hline Tertile 1 & $\leq 113656$ \\
\hline Tertile 2 & $1136567-140717$ \\
\hline Tertile3 & $\geq 140718$ \\
\hline Nursing home residence* & $34268(18.5)$ \\
\hline Social allowance* & $741(0.4)$ \\
\hline
\end{tabular}

*During 1 year preceding the initiation of the antidepressant therapy.

associated with suicidal behaviours. The risks of both fatal and non-fatal suicidal behaviours were lower among those who lived in nursing homes when initiating their antidepressant therapy. No association was found between the type of healthcare facility where antidepressant treatment was initiated and suicidal behaviours. 
Table 2 Characteristics of healthcare facility issuing the index antidepressant prescription for new users of antidepressants aged 75 and above $(n=185225)$

\begin{tabular}{|c|c|c|c|}
\hline Characteristics & N (\%) & $\begin{array}{l}\text { Suicide } \\
(n=295)\end{array}$ & $\begin{array}{l}\text { Attempted } \\
\text { suicide } \\
\text { ( } n=654)\end{array}$ \\
\hline \multicolumn{4}{|l|}{ Type of care } \\
\hline $\begin{array}{l}\text { Primary/ambulatory } \\
\text { care }\end{array}$ & 99338 (53.6) & 169 & 327 \\
\hline $\begin{array}{l}\text { Specialised } \\
\text { outpatient care }\end{array}$ & $56966(30.8)$ & 86 & 204 \\
\hline Inpatient care & 21813 (11.8) & 32 & 89 \\
\hline Other & $6925(3.7)$ & 8 & 34 \\
\hline Missing & $183(0.1)$ & 0 & 2 \\
\hline \multicolumn{4}{|l|}{ Sphere of activity } \\
\hline Primary care & $125183(67.6)$ & 198 & 386 \\
\hline Internal medicine & $18316(9.9)$ & 23 & 64 \\
\hline Geriatric care & $9616(5.2)$ & 8 & 29 \\
\hline Psychiatry care & $9363(5.1)$ & 18 & 37 \\
\hline Neurology & $1815(1.0)$ & 2 & 6 \\
\hline Home care & $1206(0.7)$ & 0 & 5 \\
\hline Oncology & $908(0.5)$ & 0 & 0 \\
\hline Emergency care & $968(0.5)$ & 2 & 6 \\
\hline Intensive care & $628(0.3)$ & 0 & 0 \\
\hline $\begin{array}{l}\text { Convalescent/day } \\
\text { care }\end{array}$ & $236(0.1)$ & 0 & 0 \\
\hline Palliative care & $270(0.1)$ & 0 & 0 \\
\hline Other & 12533 (6.8) & 44 & 121 \\
\hline Missing & $183(0.1)$ & 0 & 2 \\
\hline
\end{tabular}

Differences unfolded in the gender stratified analyses (table 4 ). In men, the risk of suicide was lower among the oldest $(0.45,95 \%$ CI 0.24 to 0.85$)$. This risk was however higher among those who were single $(1.81,95 \%$ CI 1.13 to $2.89)$ or divorced $(1.58,95 \%$ CI 1.06 to 2.36$)$. Such differences were not found among women. Women who had a lower white-collar or a blue-collar occupation before retirement had lower risk of suicide compared with those with upper white-collar positions.

Regarding factors associated with suicide attempt (table 5), for women a lower risk was observed for those aged 90 and above. Suicide attempts were more common among men born in another Nordic country $(1.59,95 \%$ CI 1.02 to 2.46), and women born outside of Nordic countries $(1.65,95 \%$ CI 1.12 to 2.41$)$. Women with the highest education level had a higher risk of suicide attempt (1.98, $95 \%$ CI 1.43 to 2.75 ).

\section{DISCUSSION}

Higher risks of fatal and non-fatal suicidal behaviours were observed among the "younger" older adults (75-79 years), and suicide attempts were more common among new users of antidepressants born in a foreign country.
In the gender-stratified analyses, being single or divorced was associated with elevated risk of suicide among men. Educational and occupational history influenced risk of suicidal behaviours in women only.

We found lower risk of suicidal behaviour among those aged $\geq 85$ years compared with those aged $75-79$ years old. This was somewhat unexpected as higher rates of suicide are observed in those aged $85+$ in the general population. We could identify no previous studies focusing on new users of antidepressants for comparison. Our population of new users of antidepressant may differ from their peers in the general population since late-life depression is associated with vascular, neuroanatomical and inflammatory risk factors, as well as anxiety, dementia and sleep disorders. ${ }^{20}$ However, we could not compare the medical characteristics of our population with all Swedish residents aged $\geq 75$ years since these data were not available in our dataset. After the age of 85, a large proportion of the population has dementia, ${ }^{21}$ one of the few psychiatric diagnoses not related to elevated suicide risk. ${ }^{22}$ Also, it must be remembered that the very old in this study represent a survival population. Nonagenarians and centenarians alive today have benefited from a number of factors that have contributed to prolonged life expectancy, such as healthier lifestyle, better health conditions and caretaking. All this may have a positive effect on their quality of life and thus on the suicide rate in the oldest age groups.

Our result regarding higher risk of suicide attempts among foreign-born older adults extends the findings of mixed-age studies conducted in Sweden and other Western countries. ${ }^{23-25}$ The higher risk of suicide attempt among those born in other Nordic countries may in part be related to the fact that high suicide attempt rates are observed in immigrants from Finland, who constituted a large proportion of immigrants, compared with the native Swedish population. ${ }^{2627}$ The authors of a recent meta-analysis reported substantial continuity between the suicide rates in the country of birth and those of the country of immigration. ${ }^{28}$ Cultural factors including attitudes to suicide and lifestyle may also play a role for the higher suicide rates among Nordic-born immigrants. We have previously shown increased risk of both fatal and non-fatal suicidal behaviours in older adults with alcohol-use disorders, ${ }^{29}$ and differential rates of alcohol consumption may be a partial explanation. ${ }^{30}$ The higher risk of suicide attempt among those born in non-Nordic countries may be explained by life conditions that we were unable to capture in our study, such as refugee status, post-traumatic stress, migration experience and an experience of being distanced from Swedish society. ${ }^{31}$ Social isolation in terms of limited social network, language limitation and sparse contact with family members may also be relevant to explain elevated rates of suicidal behaviour among the oldest adults born in non-Nordic countries. However, the gender difference in the association between the country of birth and suicidal behaviours warrants more research to better elucidate this association. 
Table 3 Factors associated with suicide and suicide attempt among new users of antidepressants aged 75 and above $(n=185015)^{*}$

\begin{tabular}{|c|c|c|c|c|}
\hline \multirow[b]{2}{*}{ Variable } & \multicolumn{2}{|l|}{ Suicide $\mathrm{n}=\mathbf{2 9 5}$} & \multicolumn{2}{|c|}{ Suicide attempt $n=654$} \\
\hline & $\begin{array}{l}\text { Crude SHR } \\
(95 \% \mathrm{Cl})\end{array}$ & $\begin{array}{l}\text { Adjusted SHR† } \\
(95 \% \mathrm{Cl})\end{array}$ & $\begin{array}{l}\text { Crude SHR } \\
(95 \% \mathrm{Cl})\end{array}$ & $\begin{array}{l}\text { Adjusted SHR† } \\
(95 \% \mathrm{Cl})\end{array}$ \\
\hline Men & 4.18 (3.26 to 5.36$)$ & 3.56 (2.67 to 4.73 ) & 1.70 (1.46 to 1.99$)$ & 1.41 (1.17 to 1.68$)$ \\
\hline \multicolumn{5}{|l|}{ Age group (years) } \\
\hline $75-79$ & 1 (Reference) & 1 (Reference) & 1 (Reference) & 1 (Reference) \\
\hline $80-84$ & 0.74 (0.56 to 0.97$)$ & 0.80 (0.60 to 1.05$)$ & 0.78 (0.65 to 0.94$)$ & $0.83(0.69$ to 1.00$)$ \\
\hline $85-89$ & 0.61 (0.45 to 0.82$)$ & 0.73 (0.53 to 0.99$)$ & 0.66 (0.54 to 0.81$)$ & 0.75 (0.61 to 0.94$)$ \\
\hline$\geq 90$ & $0.36(0.23$ to 0.56$)$ & 0.53 (0.33 to 0.86$)$ & 0.42 (0.32 to 0.57$)$ & 0.58 (0.43 to 0.79$)$ \\
\hline \multicolumn{5}{|l|}{ Country of birth } \\
\hline Sweden & 1 (Reference) & 1 (Reference) & 1 (Reference) & 1 (Reference) \\
\hline Nordic countries (except Sweden) & 1.46 (0.94 to 2.28$)$ & 1.38 (0.87 to 2.21$)$ & $1.62(1.21$ to 2.17$)$ & $1.58(1.16$ to 2.15$)$ \\
\hline Non-Nordic countries & $0.60(0.30$ to 1.21$)$ & 0.64 (0.31 to 1.30$)$ & 1.57 (1.15 to 2.13$)$ & $1.43(1.06$ to 1.93$)$ \\
\hline \multicolumn{5}{|l|}{ Marital status } \\
\hline Married & 1 (Reference) & 1 (Reference) & 1 (Reference) & 1 (Reference) \\
\hline Single & $1.42(0.96$ to 2.10$)$ & 1.81 (1.21 to 2.70$)$ & 0.73 (0.51 to 1.05$)$ & 0.90 (0.62 to 1.30$)$ \\
\hline Widow/widower & 0.50 (0.38 to 0.66$)$ & $1.00(0.74$ to 1.35$)$ & 0.76 (0.64 to 0.90$)$ & 1.09 (0.90 to 1.33$)$ \\
\hline Divorced & $1.08(0.77$ to 1.50$)$ & $1.43(1.02$ to 2.01$)$ & 0.92 (0.72 to 1.18$)$ & $1.02(0.79$ to 1.31$)$ \\
\hline \multicolumn{5}{|l|}{ Highest level of education } \\
\hline Mandatory ( $\leq 9$ years) & 1 (Reference) & 1 (Reference) & 1 (Reference) & 1 (Reference) \\
\hline Secondary & 0.72 (0.52 to 0.99$)$ & 0.71 (0.51 to 0.99$)$ & 1.05 (0.86 to 1.28$)$ & 0.99 (0.81 to 1.22$)$ \\
\hline Higher education & 1.59 (1.22 to 2.07$)$ & 1.14 (0.81 to 1.59$)$ & 1.86 (1.55 to 2.22$)$ & 1.60 (1.27 to 2.01$)$ \\
\hline \multicolumn{5}{|l|}{ Last registered occupation } \\
\hline Upper white collar & 1 (Reference) & 1 (Reference) & 1 (Reference) & 1 (Reference) \\
\hline Lower white collar & $0.60(0.40$ to 0.90$)$ & 1.04 (0.67 to 1.61$)$ & 0.81 (0.63 to 1.05$)$ & 1.19 (0.90 to 1.57$)$ \\
\hline Blue collar & 0.64 (0.49 to 0.84$)$ & 0.83 (0.59 to 1.17$)$ & 0.66 (0.55 to 0.80$)$ & 0.98 (0.78 to 1.24$)$ \\
\hline \multicolumn{5}{|l|}{ Annual income } \\
\hline Tertile 1 & 1 (Reference) & 1 (Reference) & 1 (Reference) & 1 (Reference) \\
\hline Tertile 2 & 1.17 (0.87 to 1.57$)$ & 0.90 (0.66 to 1.21$)$ & 1.15 (0.94 to 1.39$)$ & 1.08 (0.88 to 1.33$)$ \\
\hline Tertile 3 & 1.49 (1.12 to 1.97$)$ & 0.77 (0.55 to 1.07$)$ & 1.40 (1.16 to 1.69$)$ & $1.01(0.80$ to 1.27$)$ \\
\hline Nursing home residence & 0.21 (0.11 to 0.43$)$ & 0.25 (0.12 to 0.52$)$ & 0.17 (0.10 to 0.29$)$ & 0.21 (0.13 to 0.36$)$ \\
\hline \multicolumn{5}{|c|}{ Type of the healthcare facility issuing the index prescription } \\
\hline Primary care & 1 (Reference) & 1 (Reference) & 1 (Reference) & 1 (Reference) \\
\hline Specialised ambulatory care & 0.99 (0.77 to 1.28$)$ & $0.95(0.74$ to 1.23$)$ & 1.09 (0.92 to 1.30$)$ & $1.10(0.92$ to 1.31$)$ \\
\hline Inpatient care & 0.92 (0.63 to 1.33$)$ & $0.71(0.49$ to 1.03$)$ & 1.21 (0.96 to 1.54$)$ & 1.07 (0.84 to 1.35$)$ \\
\hline Other & $0.67(0.33$ to 1.35$)$ & 0.64 (0.31 to 1.29$)$ & 1.41 (0.99 to 2.00$)$ & $1.36(0.95$ to 1.93$)$ \\
\hline
\end{tabular}

*Due to partially missing data, 210 persons were excluded from the regression analysis.

†Also adjusted for age, sex, suicide attempt within 1 year preceding the index date, country of birth, marital status, nursing home residence, highest level of education, last registered occupation, annual income and type of facility issuing the index medication.

SHR, sub-hazard ratio.

In our gender-stratified analysis, being single or divorced had a significant effect on suicide risk among men but not among women. While we could find no study focusing on depressed older adults for comparison, one partial explanation of our findings may be that depressed old men living alone may be more prone to social isolation than their female counterparts. ${ }^{32}$ Another issue might be men's unwillingness to seek mental health services, ${ }^{33}$ and living alone probably reduces their motivation to seek care. Partner loss was not associated with suicidal behaviour in our study. One Danish cohort study found increased risk for suicide among the oldest widowed, especially among men. ${ }^{34}$ However, the study included only deaths of partners that occurred during a 
Table 4 Factors associated with suicide among new users of antidepressants aged 75 and above stratified by gender $(n=185015)^{*}$

\begin{tabular}{|c|c|c|c|c|}
\hline \multirow[b]{2}{*}{ Variable } & \multicolumn{2}{|l|}{$\begin{array}{l}\text { Men, suicide } n=199 \\
n=67539\end{array}$} & \multicolumn{2}{|c|}{$\begin{array}{l}\text { Women, suicide } n=96 \\
n=117476\end{array}$} \\
\hline & $\begin{array}{l}\text { Crude SHR } \\
(95 \% \mathrm{Cl})\end{array}$ & $\begin{array}{l}\text { Adjusted SHR† } \\
(95 \% \mathrm{Cl})\end{array}$ & $\begin{array}{l}\text { Crude SHR } \\
(95 \% \mathrm{Cl})\end{array}$ & $\begin{array}{l}\text { Adjusted SHR† } \\
(95 \% \mathrm{Cl})\end{array}$ \\
\hline \multicolumn{5}{|l|}{ Age group (years) } \\
\hline $75-79$ & 1 (Reference) & 1 (Reference) & 1 (Reference) & 1 (Reference) \\
\hline $80-84$ & 0.88 (0.63 to 1.22$)$ & 0.90 (0.64 to 1.25$)$ & 0.57 (0.34 to 0.91$)$ & 0.62 (0.37 to 1.03$)$ \\
\hline $85-89$ & 0.75 (0.52 to 1.08$)$ & 0.80 (0.55 to 1.16$)$ & 0.48 (0.28 to 0.82$)$ & $0.62(0.35$ to 1.11$)$ \\
\hline$\geq 90$ & 0.38 (0.20 to 0.72 ) & 0.45 (0.24 to 0.85$)$ & 0.43 (0.22 to 0.83$)$ & 0.65 (0.30 to 1.41$)$ \\
\hline \multicolumn{5}{|l|}{ Country of birth } \\
\hline Sweden & 1 (Reference) & 1 (Reference) & 1 (Reference) & 1 (Reference) \\
\hline $\begin{array}{l}\text { Nordic countries (except } \\
\text { Sweden) }\end{array}$ & 1.40 (0.79 to 2.45$)$ & 1.24 (0.68 to 2.27$)$ & 1.71 (0.83 to 3.53$)$ & $1.70(0.80$ to 3.60$)$ \\
\hline Non-Nordic countries & 0.56 (0.21 to 1.51$)$ & 0.52 (0.19 to 1.42$)$ & 0.84 (0.31 to 2.29$)$ & 0.84 (0.30 to 2.33$)$ \\
\hline \multicolumn{5}{|l|}{ Marital status } \\
\hline Married & 1 (Reference) & 1 (Reference) & 1 (Reference) & 1 (Reference) \\
\hline Single & 1.67 (1.06 to 2.65$)$ & 1.81 (1.13 to 2.89 ) & 1.27 (0.59 to 2.74$)$ & 1.46 (0.65 to 3.26$)$ \\
\hline Widow/widower & 0.92 (0.64 to 1.32) & 1.15 (0.79 to 1.65$)$ & 0.57 (0.36 to 0.91$)$ & 0.75 (0.44 to 1.29$)$ \\
\hline Divorced & 1.52 (1.02 to 2.27$)$ & 1.58 (1.06 to 2.36$)$ & 0.96 (0.52 to 1.78$)$ & $1.02(0.53$ to 1.94$)$ \\
\hline \multicolumn{5}{|l|}{ Highest level of education } \\
\hline Mandatory ( $\leq 9$ years) & 1 (Reference) & 1 (Reference) & 1 (Reference) & 1 (Reference) \\
\hline Secondary & 0.71 (0.46 to 1.09$)$ & 0.71 (0.46 to 1.10$)$ & 0.85 (0.51 to 1.41$)$ & $0.68(0.40$ to 1.17$)$ \\
\hline Higher education & 1.17 (0.86 to 1.59$)$ & 1.30 (0.88 to 1.91$)$ & 1.47 (0.87 to 2.50$)$ & 0.66 (0.34 to 1.28$)$ \\
\hline \multicolumn{5}{|l|}{ Last registered occupation } \\
\hline Upper white collar & 1 (Reference) & 1 (Reference) & 1 (Reference) & 1 (Reference) \\
\hline Lower white collar & 1.22 (0.70 to 2.12$)$ & 1.37 (0.78 to 2.42$)$ & 0.55 (0.30 to 1.01$)$ & 0.50 (0.26 to 0.96$)$ \\
\hline Blue collar & $1.02(0.74$ to 1.41$)$ & 1.14 (0.76 to 1.70$)$ & 0.40 (0.24 to 0.65$)$ & 0.35 (0.20 to 0.61$)$ \\
\hline \multicolumn{5}{|l|}{ Annual income } \\
\hline Tertile 1 & 1 (Reference) & 1 (Reference) & 1 (Reference) & 1 (Reference) \\
\hline Tertile 2 & $0.82(0.55$ to 1.21$)$ & 0.80 (0.54 to 1.18$)$ & 1.05 (0.67 to 1.66$)$ & 1.09 (0.67 to 1.78$)$ \\
\hline Tertile 3 & 0.81 (0.56 to 1.16$)$ & 0.74 (0.49 to 1.11$)$ & 1.00 (0.60 to 1.69$)$ & 0.82 (0.45 to 1.49$)$ \\
\hline Nursing home residence & $0.23(0.09$ to 0.56$)$ & 0.24 (0.10 to 0.59$)$ & $0.23(0.07$ to 0.72$)$ & $0.28(0.08$ to 0.94$)$ \\
\hline \multicolumn{5}{|c|}{ Type of the healthcare facility issuing the index prescription } \\
\hline Primary care & 1 (Reference) & 1 (Reference) & 1 (Reference) & 1 (Reference) \\
\hline Specialised ambulatory care & $0.93(0.68$ to 1.27$)$ & $0.93(0.68$ to 1.27$)$ & 0.99 (0.63 to 1.55$)$ & 0.99 (0.63 to 1.56$)$ \\
\hline Inpatient care & 0.75 (0.48 to 1.17$)$ & 0.68 (0.44 to 1.05$)$ & 0.90 (0.45 to 1.83$)$ & 0.81 (0.40 to 1.65$)$ \\
\hline Other & 0.47 (0.17 to 1.29$)$ & 0.47 (0.17 to 1.27$)$ & 1.02 (0.37 to 2.82$)$ & 1.01 (0.37 to 2.80$)$ \\
\hline
\end{tabular}

*Due to partially missing data, 210 persons were excluded from the regression analysis.

$\ddagger$ Also adjusted for age, sex, suicide attempt, country of birth, marital status, nursing home residence, highest level of education, last registered occupation, annual income and type of facility issuing the index medication.

SHR, sub-hazard ratio.

5-year observation period. It may therefore not be relevant to compare the findings of the two studies.

The higher risk of suicidal behaviours among women with higher education and those who have had positions requiring more advanced qualifications is a new finding. Most previous research on socioeconomic status and suicidal behaviours in late life has overlooked the gender dimension and gender-stratified studies have yielded disparate results. ${ }^{83536}$ Our results support the need for a life-course approach to better understand and prevent late-life suicidal behaviours. ${ }^{20}$ As pointed out by Alexopoulos, ${ }^{37}$ even if there is a late onset form of depression, recurrent depressive episodes may arise in older patients who have experienced life stressors and depression earlier 
Table 5 Factors associated with suicide attempt among new users of antidepressants aged 75 and above stratified by gender $(n=185015)^{*}$

Men, suicide attempt $\mathrm{n}=\mathbf{3 0 0}$

$\mathrm{n}=67539$

\section{Adjusted SHR†}

Variable

Age group (years)

$75-79$

$80-84$

85-89

$\geq 90$

Crude SHR $(95 \% \mathrm{Cl}) \quad(95 \% \mathrm{Cl})$
Women, suicide attempt $\mathrm{n}=354$ $n=117476$

\begin{tabular}{ll}
\hline Crude SHR $(95 \% \mathrm{Cl})$ & $\begin{array}{l}\text { Adjusted SHRT } \\
(95 \% \mathrm{Cl})\end{array}$
\end{tabular}

Crude SHR $(95 \% \mathrm{Cl}) \quad(95 \% \mathrm{Cl})$

Country of birth

\begin{tabular}{|c|c|c|c|c|}
\hline Sweden & 1 (Reference) & 1 (Reference) & 1 (Reference) & 1 (Reference) \\
\hline $\begin{array}{l}\text { Nordic countries (except } \\
\text { Sweden) }\end{array}$ & 1.72 (1.13 to 2.64$)$ & 1.59 (1.02 to 2.46$)$ & 1.57 (1.05 to 2.34$)$ & 1.32 (0.87 to 2.00$)$ \\
\hline Non-Nordic countries & 1.47 (0.87 to 2.47$)$ & 1.46 (0.86 to 2.47$)$ & $1.72(1.17$ to 2.51$)$ & 1.65 (1.12 to 2.41$)$ \\
\hline \multicolumn{5}{|l|}{ Marital status } \\
\hline Married & 1 (Reference) & 1 (Reference) & 1 (Reference) & 1 (Reference) \\
\hline Single & 0.78 (0.47 to 1.28$)$ & 0.96 (0.58 to 1.59$)$ & 0.71 (0.42 to 1.22$)$ & 0.81 (0.47 to 1.39 ) \\
\hline Widow/widower & 1.00 (0.75 to 1.31$)$ & 1.22 (0.92 to 1.62$)$ & 0.77 (0.61 to 0.98$)$ & 1.02 (0.78 to 1.34$)$ \\
\hline Divorced & 1.04 (0.72 to 1.49$)$ & 1.06 (0.74 to 1.54$)$ & 0.92 (0.65 to 1.30$)$ & 0.94 (0.65 to 1.34$)$ \\
\hline \multicolumn{5}{|l|}{ Highest level of education } \\
\hline Mandatory ( $\leq 9$ years) & 1 (Reference) & 1 (Reference) & 1 (Reference) & 1 (Reference) \\
\hline Secondary & 0.97 (0.70 to 1.35$)$ & 0.92 (0.66 to 1.28$)$ & 1.14 (0.88 to 1.47$)$ & 1.03 (0.79 to 1.35$)$ \\
\hline Higher education & 1.49 (1.16 to 1.91$)$ & 1.32 (0.98 to 1.80$)$ & 2.08 (1.60 to 2.70$)$ & 1.98 (1.43 to 2.75$)$ \\
\hline \multicolumn{5}{|l|}{ Last registered occupation } \\
\hline Upper white collar & 1 (Reference) & 1 (Reference) & 1 (Reference) & 1 (Reference) \\
\hline Lower white collar & 0.81 (0.50 to 1.32$)$ & 0.95 (0.58 to 1.57$)$ & 0.92 (0.66 to 1.29$)$ & 1.31 (0.91 to 1.90$)$ \\
\hline Blue collar & 0.75 (0.58 to 0.97$)$ & 0.98 (0.72 to 1.32$)$ & 0.66 (0.49 to 0.88$)$ & 1.03 (0.72 to 1.46$)$ \\
\hline \multicolumn{5}{|l|}{ Annual income } \\
\hline Tertile 1 & 1 (Reference) & 1 (Reference) & 1 (Reference) & 1 (Reference) \\
\hline Tertile 2 & 1.12 (0.78 to 1.62$)$ & 1.14 (0.78 to 1.67$)$ & 1.09 (0.86 to 1.39$)$ & 1.11 (0.86 to 1.44$)$ \\
\hline Tertile 3 & 1.38 (0.99 to 1.93$)$ & 1.23 (0.85 to 1.79$)$ & 1.11 (0.85 to 1.46$)$ & 0.88 (0.64 to 1.22$)$ \\
\hline Nursing home residence & 0.18 (0.08 to 0.41$)$ & 0.23 (0.11 to 0.48$)$ & 0.16 (0.08 to 0.33$)$ & $0.21(0.10$ to 0.41$)$ \\
\hline Primary care & 1 (Reference) & 1 (Reference) & 1 (Reference) & 1 (Reference) \\
\hline Specialised ambulatory care & 0.93 (0.68 to 1.27$)$ & 1.31 (1.01 to 1.69$)$ & 0.91 (0.72 to 1.17$)$ & 0.94 (0.74 to 1.20$)$ \\
\hline Inpatient care & 0.75 (0.48 to 1.17$)$ & 1.15 (0.83 to 1.62$)$ & 1.08 (0.77 to 1.53$)$ & 1.01 (0.72 to 1.42$)$ \\
\hline Other & $0.47(0.17$ to 1.29$)$ & 1.14 (0.63 to 2.06$)$ & 1.54 (0.99 to 2.39$)$ & 1.52 (0.97 to 2.36$)$ \\
\hline
\end{tabular}

*Due to partially missing data, 210 persons were excluded from the regression analysis.

†Also adjusted for age, sex, suicide attempt, country of birth, marital status, nursing home residence, highest level of education, last registered occupation, annual income and type of facility issuing the index medication.

SHR, sub-hazard ratio.

in life. A large prospective cohort study with over 50 years of follow-up and a wide range of life course measures and job characteristics has found that women in leadership positions at the time of retirement were significantly more exposed to job-related stressors than lower status women and men in both positions. ${ }^{38}$ Women who had higher education and leadership positions have often experienced a work environment highly dominated by men, and as such might have experienced higher demands for excellent work performances. These demands combined with a possible tendency to adapt to ideals that traditionally have been associated with men and masculinity might put these women in a more vulnerable situation. For example, they might experience conflicting roles, or loss of social status, in the context of retirement. When faced with functional limitations, they might feel that they 
are better off dead than having compromised autonomy. Further, they might have restricted their social networks to manage demanding work situations prior to retirement, resulting in a more limited social situation after retirement. Despite the social advantages that women with higher socioeconomic status may have had, the gendered macrolevel and mesolevel social contexts may have limited the extent to which women in higher-status positions have derived psychological benefits from their socioeconomic situation. ${ }^{38} 39$

New users of antidepressants who resided in nursing homes had lower risks of both fatal and non-fatal suicidal behaviours compared with their peers living in the community. A partial explanation might be that nursing home staff are more able to monitor older adults who are on treatment for depression. ${ }^{40}$ Being in a nursing home provides the older adults with a social network, which may reduce feelings of loneliness. Further, many of the new users of antidepressants residing in nursing homes might have been prescribed antidepressants for behavioural symptoms of dementia, rather than for depression. ${ }^{22}$

The sociodemographic factors associated with fatal or non-fatal suicidal behaviours in new users of antidepressants in our study (eg, male sex, level of education, occupational history in women and country of birth) seem less susceptible to a reverse causality. Therefore, the interpretation of our results should take into account the underlying assumption that the associations between the exposures and suicidal behaviours are unidirectional. However, more research is needed on possible mechanisms and mediators influencing these associations. Variables analysed in this study may also be proxies for non-measured risk factors for suicide in older adults distributed over social and economic living conditions. Medical comorbidity, chronic pain, frailty and cognitive impairment, as well as prolonged grief may be amplified by depression to a higher extent in persons in constrained socioeconomic situations. The combined effects of depression, comorbidities, functional limitations and social factors should thus be taken into consideration in the evaluation of suicide risk in older adults.

\section{Strengths and limitations}

The use of national population-based data means that there are no exclusion criteria. This minimises the risk of selection bias that may potentially result from the sole use of hospital-based data. Our study was sufficiently large to explore the association of numerous sociodemographic variables with fatal and non-fatal suicidal behaviours. Register-based studies on suicidal behaviours rely on collection of data from many different settings and variations in data validity can occur. An important limitation is that only suicide attempts that have been registered in hospitals or specialised outpatient services can be captured with our study design. Despite the wide range of covariates included in the analyses, information on other potential confounders such as health behaviours including alcohol consumption was not available.
Gender-stratified analyses should be interpreted with caution due to the low number of suicides, especially among women and therefore low power. Education, income and last occupational class measure different social dimensions and tap into different causal mechanisms related to health. ${ }^{41}$ Their possible correlation does not affect the validity of the regression models or other predictors. It may however decrease the statistical power of the analyses.

One strength of our research is the investigation of suicidal behaviours in 5 year age bands after the age of 75 years. This is particularly relevant due to the ageing of populations worldwide. A previous study found that suicide rates slightly increased again in the 100 years age band. ${ }^{42}$ Due to the low number of centenarians in our study, we could not investigate the risk of suicidal behaviours in this age group.

We had access to information about the initiation of antidepressants to define our population but we acknowledge that using this method is not the same as using structured clinical interviews or diagnostic criteria to define depression, and we therefore do not rule out an indication bias or a residual confounding. Antidepressants are prescribed for the treatment of depression and for anxiety disorders and obsessive-compulsive disorder as well as behavioural symptoms of dementia. Further, the Swedish Prescribed Drug Register does not include drugs administered in a hospital setting which may lead to a slight misclassification of those who initiated their antidepressant therapy during their hospitalisation. However, only $4.3 \%$ of the study population had a record of depression in inpatient/outpatient specialised care during the year preceding their inclusion in the study. Antidepressant treatment initiated in hospital will in most cases be followed up with continuation treatment after discharge, and thus recorded in the Swedish Prescribed Drug Register. This would suggest only a marginal effect on our findings. Furthermore, being married does not inform about the actual support received from the partner, and it is possible that age-related changes that affect one or both partners can burden the relationship. Therefore, it seems possible that some of the observed associations of the marital status and suicidal behaviours could be explained, at least in part, by unmeasured factors. Another limitation is that, when considering findings related to immigrant status, we did not have information about the date of immigration, which may have influenced degree of acculturation and assimilation to the hosting country, ${ }^{43}$ which in turn could impact on suicidal behaviours. Due to power issues, a more detailed analysis of region of birth was not possible. Data on suicides and attempted suicides by region of birth are reported in the online supplementary appendix 2 . The influence of race and ethnicity on suicidal behaviour could not be investigated in our study as those born in Sweden and other Nordic countries may be considered ethnically rather homogeneous. 


\section{Implications}

While our findings cannot be extrapolated to older adults not taking antidepressants, or long-term users of these drugs, they offer clues to the prevention of suicidal behaviours in persons recently identified as depressed and in need of treatment. Our findings highlight the need for gender-specific, multifaceted approaches to the prevention of suicidal behaviours in late life. The identification and treatment of late-life depression remain an important target for suicide prevention in our oldest adults, but the current findings highlight the need for new initiatives that go beyond the healthcare sphere.

Research is needed in other settings as socioeconomic conditions, availability of healthcare and cultural differences may have an impact on risk of both fatal and non-fatal suicidal behaviours in late life.

\section{Author affiliations}

${ }^{1}$ Department of Psychiatry and Neurochemistry, Institute of Neuroscience and Physiology, Sahlgrenska Academy, Gothenburg University, Gothenburg, Sweden ${ }^{2}$ Section of Epidemiology and Social Medicine, Department of Public Health and Community Medicine at Institute of Medicine, University of Gothenburg, Gothenburg, Sweden

${ }^{3}$ Medical Evidence and Observational Research, AstraZeneca, Mölndal, Sweden ${ }^{4}$ Health Metrics, Sahlgrenska Academy, University of Gothenburg, Gothenburg, Sweden

Contributors KH conceived and designed the study, helped acquire the data, helped with data analysis and interpretation of results, drafted the article and had the final approval for submission. KAS conceived and designed the study, helped acquire the data, helped with data analysis, revised the article for content and gave the final approval for submission. GH and IS helped with interpretation of results, revised the article for content and gave the final approval for submission. SG performed data analysis, revised the article for content and gave the final approval for submission. MW is the primary investigator of the project. She conceived and designed the study, helped acquire the data, helped with interpretation of results, revised the article for content and gave the final approval for submission. All authors had full access to all of the data (including statistical reports and tables) and can take responsibility for the integrity of the data and the accuracy of the data analysis. $\mathrm{KH}$ is the guarantor.

Funding MW received grants from the Swedish Research Council (VR) 201601590, the Swedish Research Council for Health, Working Life and Welfare (Forte) 2016-07097, and ALFGBG-715841. KAS received a grant from the SöderströmKönig Foundation SLS-483251. IS received grants from Forte (2013-2300, 20132496), Swedish Research Council (2015-02830) and Sahlgrenska University Hospital (ALF)

Competing interests KAS is employed by AstraZeneca. However, the views expressed in this study are her own and not those of AstraZeneca.

Patient consent Not required.

Ethics approval This study was approved by the Regional Ethical Review Board in Gothenburg (№: 111-15).

Provenance and peer review Not commissioned; externally peer reviewed.

Data sharing statement № additional data available.

Open access This is an open access article distributed in accordance with the Creative Commons Attribution Non Commercial (CC BY-NC 4.0) license, which permits others to distribute, remix, adapt, build upon this work non-commercially, and license their derivative works on different terms, provided the original work is properly cited, appropriate credit is given, any changes made indicated, and the use is non-commercial. See: http://creativecommons.org/licenses/by-nc/4.0/.

\section{REFERENCES}

1. Bertolote JM, De Leo D. Global suicide mortality rates - a light at the end of the tunnel? Crisis 2012;33:249-53.
2. Beautrais AL. A case control study of suicide and attempted suicide in older adults. Suicide Life Threat Behav 2002;32:1-9.

3. Okolie C, Dennis M, Simon Thomas E, et al. A systematic review of interventions to prevent suicidal behaviors and reduce suicidal ideation in older people. Int Psychogeriatr 2017;29:1801-24.

4. Lapierre S, Erlangsen A, Waern M, et al. A systematic review of elderly suicide prevention programs. Crisis 2011;32:88-98.

5. Mann JJ, Apter A, Bertolote J, et al. Suicide prevention strategies: a systematic review. JAMA 2005;294:2064-74.

6. Statistics Sweden, 2016. Statistics on Causes of Death 2015 [In Swedish] http://www.socialstyrelsen.se/publikationer2016/2016-8-4. (accessed 12 Feb 2018).

7. O'Connell H, Chin AV, Cunningham C, et al. Recent developments: suicide in older people. BMJ 2004;329:895-9.

8. Fässberg MM, van Orden KA, Duberstein P, et al. A systematic review of social factors and suicidal behavior in older adulthood. Int $J$ Environ Res Public Health 2012;9:722-45.

9. Rubenowitz E, Waern M, Wilhelmson K, et al. Life events and psychosocial factors in elderly suicides--a case-control study. Psychol Med 2001;31:1193-202.

10. Fleischmann A. A global perspective in the epidemiology of suicide. Suicidologi 2015;7:6-8.

11. Waern M, Rubenowitz E, Wilhelmson K. Predictors of suicide in the old elderly. Gerontology 2003;49:328-34.

12. Erlangsen A, Bille-Brahe U, Jeune B. Differences in suicide between the old and the oldest old. J Gerontol B Psychol Sci Soc Sci 2003:58:S314-22.

13. Aarts N, Noordam R, Hofman A, et al. Self-reported indications for antidepressant use in a population-based cohort of middle-aged and elderly. Int J Clin Pharm 2016;38:1311-7.

14. Wong J, Motulsky A, Eguale T, et al. Treatment indications for antidepressants prescribed in primary care in Quebec, Canada, 2006-2015. JAMA 2016;315:2230-2.

15. Gardarsdottir H, Heerdink ER, van Dijk L, et al. Indications for antidepressant drug prescribing in general practice in the Netherlands. J Affect Disord 2007;98:109-15.

16. Wettermark B, Hammar N, Fored CM, et al. The new Swedish Prescribed Drug Register--opportunities for pharmacoepidemiological research and experience from the first six months. Pharmacoepidemiol Drug Saf 2007;16:726-35.

17. Fine JP, Gray RJ. A proportional hazards model for the subdistribution of a competing risk. J Am Stat Assoc 1999;94:496-509.

18. Van Orden KA, Wiktorsson $S$, Duberstein $\mathrm{P}$, et al. Reasons for attempted suicide in later life. Am J Geriatr Psychiatry 2015;23:536-44.

19. Hedna K, Andersson Sundell K, Hamidi A, et al. Antidepressants and suicidal behaviour in late life: a prospective population-based study of use patterns in new users aged 75 and above. Eur $J$ Clin Pharmacol 2018;74:201-8.

20. Fiske A, Wetherell JL, Gatz M. Depression in older adults. Annu Rev Clin Psychol 2009;5:363-89.

21. Corrada MM, Brookmeyer R, Paganini-Hill A, et al. Dementia incidence continues to increase with age in the oldest old: the 90+ study. Ann Neurol 2010;67:114-21.

22. Haw C, Harwood D, Hawton K. Dementia and suicidal behavior: a review of the literature. Int Psychogeriatr 2009;21:440-53.

23. Sundaram V, Qin P, Zøllner L. Suicide risk among persons with foreign background in Denmark. Suicide Life Threat Behav 2006;36:481-9.

24. Johansson LM, Sundquist J, Johansson SE, et al. Suicide among foreign-born minorities and Native Swedes: an epidemiological follow-up study of a defined population. Soc Sci Med 1997;44:181-7.

25. Di Thiene D, Alexanderson K, Tinghög P, et al. Suicide among first-generation and second-generation immigrants in Sweden: association with labour market marginalisation and morbidity. $J$ Epidemiol Community Health 2015;69:467-73.

26. Statistics Sweden, 2010. Population by backgroundln (in Swedish) https://www.scb.se/Statistik/BE/BE0101/2010A01L/Utrikes_fodda. pdf (accessed 12 Feb 2018)

27. Westman J, Hasselstrom J, Johansson SE, et al. The influences of place of birth and socioeconomic factors on attempted suicide in a defined population of 4.5 million people. Arch Gen Psychiatry 2003;60:409-14.

28. Voracek M, Loibl LM. Consistency of immigrant and countryof-birth suicide rates: a meta-analysis. Acta Psychiatr Scand 2008;118:259-71.

29. Morin J, Wiktorsson S, Marlow T, et al. Alcohol use disorder in elderly suicide attempters: a comparison study. Am J Geriatr Psychiatry 2013;21:196-203. 
30. Mäkelä P, Fonager K, Hibell B, et al. Episodic heavy drinking in four Nordic countries: a comparative survey. Addiction 2001;96:1575-88.

31. Sundquist J, Johansson S-E. The influence of exile and repatriation on mental and physical health. Soc Psychiatry Psychiatr Epidemiol 1996;31:21-8.

32. Vandervoort D. Social isolation and gender. Curr Psychol 2000;19:229-36.

33. Mackenzie CS, Gekoski WL, Knox VJ. Age, gender, and the underutilization of mental health services: the influence of helpseeking attitudes. Aging Ment Health 2006;10:574-82.

34. Erlangsen A, Jeune B, Bille-Brahe U, et al. Loss of partner and suicide risks among oldest old: a population-based register study. Age Ageing 2004;33:378-83.

35. Almeida OP, Draper B, Snowdon J, et al. Factors associated with suicidal thoughts in a large community study of older adults. $\mathrm{Br} \mathrm{J}$ Psychiatry 2012;201:466-72.

36. Wiktorsson S, Runeson B, Skoog I, et al. Attempted suicide in the elderly: characteristics of suicide attempters 70 years and older and a general population comparison group. Am J Geriatr Psychiatry 2010;18:57-67.

37. Alexopoulos GS. Depression in the elderly. Lancet 2005;365:1961-70.

38. Pudrovska T, Karraker A. Gender, job authority, and depression. $J$ Health Soc Behav 2014;55:424-41.

39. Mirowsky J, Ross CE. Social causes of psychological distress. New York: Transaction Publishers, 2003.

40. Brown LM, Bongar B, Cleary KM. A profile of psychologists' views of critical risk factors for completed suicide in older adults. Prof Psychol 2004;35:90-6.

41. Geyer S, Hemström O, Peter R, et al. Education, income, and occupational class cannot be used interchangeably in social epidemiology. Empirical evidence against a common practice. $J$ Epidemiol Community Health 2006;60:804-10.

42. Shah A, Zarate-Escudero S, Bhat R, et al. Suicide in centenarians: the international landscape. Int Psychogeriatr 2014;26:1703-8.

43. Burvill PW. Migrant suicide rates in Australia and in country of birth. Psychol Med 1998;28:201-8. 